\title{
PERCEPÇÃO DOS USUÁRIOS DO PARQUEE ECOLÓGICO “JOÃO DOMINGOS COELHO” ASSIS (SP), QUANTO AO MEIO AMBIENTE E AVES, ANTES E APÓS A IMPLANTAÇÃO DE PLACAS INFORMATIVAS DA AVIFAUNA LOCAL
}

Giovanna Frederici de Mello ${ }^{1}$ Admilson Írio Ribeiro ${ }^{2}$ Solange Bongiovanni ${ }^{3}$

Resumo: A presente pesquisa traça o perfil dos usuários do Parque Ecológico "João Domingos Coelho" - Assis, SP, analisando a percepção a respeito de meio ambiente e da avifauna local, anteriormente a implantação de placas informativas e, posteriormente à fixação das mesmas contendo a descrição de hábitos alimentares, distribuição das espécies, nome cientifico e popular, ressaltando a importância da Educação Ambiental em parques. Foi aplicado um questionário, antes e após a implantação das placas, os dados foram analisados estatisticamente, concluindo que a observação de aves, assim como placas informativas são ferramentas didáticas e pedagógicas muito eficazes aos anseios educacionais.

Palavras-chave: Percepção Ambiental; Educação Ambiental; Avifauna.

\footnotetext{
${ }^{1}$ Instituto de Ciência e Tecnologia de Sorocaba (ICT/Sorocaba). UNESP Sorocaba, E-mail: giovanna.frederici@hotmail.com

2 Instituto de Ciência e Tecnologia de Sorocaba (ICT/Sorocaba). UNESP Sorocaba, E-mail: admilson@sorocaba.unesp.br

${ }^{3}$ Faculdade de Ciências e Letras de Assis. UNESP Assis, E-mail: solange@assis.unesp.br
} 


\title{
Introdução
}

As paisagens são decorrentes da inter-relação entre Sociedade e Natureza. Ela é fruto da "ação da cultura, ao longo do tempo, sobre a paisagem natural' (CORRÊA; ROSENDAHL, 1998, p.7). Segundo Dias (1993), há uns cinco milhões de anos os primeiros seres humanos que habitaram o Planeta enfrentaram inúmeras dificuldades e desafios, pois "a natureza era mais poderosa que os homens", e os afetava mais do que era afetada por eles.

\begin{abstract}
Contudo, com o intenso e descontrolado crescimento das cidades e da população mundial, cada vez mais essa interrelação entre Sociedade e Natureza foi se estreitando, desse modo, gerando consequências e alterações, causando muitos problemas ambientais que afetam a qualidade de vida das populações. A acelerada urbanização distanciou progressivamente a relação do homem com a natureza, que foi se tornando cada vez menos direta, mais conflituosa e banal (MELAZO, 2005).
\end{abstract}

A aceitação da problemática é o primeiro passo para a mudança da postura nas relações solidárias de respeito e comprometimento com a natureza. Frente a este cenário ambiental surge a necessidade de uma nova percepção da realidade, que tenha a manifestação dos princípios ambientais na educação, assim como na administração e na política (CAPRA, 1994).

Para Odum (1988), um ecossistema ecológico é qualquer unidade de área que abranja os organismos interagindo com o ambiente físico e o fluxo de energia. Entretanto, muito raramente se reconhece as cidades como ecossistemas, em outras palavras, a sociedade não entende a urbanização e a as cidades como manifestações da ecologia dos seres vivos.

É necessária uma mudança de postura do homem frente às questões ambientais. A ideia que se tem das cidades como um espaço de caos, deve ser substituída por uma nova perspectiva buscando novas formas de administrar os processos sociais que as produzem e as modificam, ou seja, os procedimentos e as ações devem compreender as especificidades dos espaços, suas relações com seus espaços de entorno e sua dinâmica social, econômica, cultural que neles ocorrem, de maneira menos predatória possível ao meio ambiente (MELAZO, 2005).

Segundo Quadros (2007) a Educação Ambiental não deve apenas preocupar-se com a aquisição de conhecimentos científicos ou com campanhas utópicas de proteção ao meio ambiente, proporcionando um processo de 
mudança de comportamento e aquisição de novos valores e conceitos convergentes à necessidade do mundo atual e suas relações com as questões sociais, econômicas, culturais ou ecológicas.

É de extrema importância a criação do pensamento e percepção ambiental, sabendo que muitas pessoas realizam atividades de lazer em ambientes naturais e mesmo mantendo esse costume, o ecossistema e suas características podem passar despercebidos. O resultado desses erros é o pouco ou nenhum conhecimento ambiental, e como consequência ainda pior, a falta de respeito com o Meio Ambiente.

Existem diversas formas de elucidar e criar uma percepção do tema Educação Ambiental, a observação de aves é um exemplo, pois é sabido que o Brasil apresenta grande diversidade de aves, estando presentes em todos os ambientes, inclusive centros urbanos, tornando a atividade muito atrativa e de fácil execução, auxiliando também na criação da relação humana com as aves mais pacífica e consciente.

Do mesmo modo, a observação de aves como prática pedagógica, trabalhada sob o âmbito da Educação Ambiental, e como uma alternativa aos conteúdos formais, apresenta um caráter interdisciplinar, podendo ser aplicada sob variados enfoques, que integram diferentes áreas do saber associadas (VIEIRA-DA-ROCHA; MOLIN, 2008).

Segundo Oliveira (2007), a prática de observação de aves pode ser feita por qualquer faixa etária, para ensino formal ou não formal, sem a obrigatoriedade da utilização de equipamentos específicos, nem de um amplo conhecimento na área ornitológica.

Nesse contexto surge à necessidade de investigar como os indivíduos se sensibilizam a respeito das questões ambientais, inserindo assim o estudo de percepção ambiental.

O processo de sensibilização deve despertar uma participação ativa da comunidade, por meio de ações pedagógicas que priorizem a criatividade e uma visão consciente dos aspectos socioculturais. Desse modo, parques urbanos compõem um ambiente ideal para que seja proposta ações ligada ao desenvolvimento da percepção e Educação Ambiental, auxiliando na mudança de atitudes e no desenvolvimento da consciência (MELAZO, 2005).

Face ao exposto, o trabalho de monografia sobre a percepção ambiental dos visitantes do Parque Ecológico "João Domingos Coelho", Assis (SP) também conhecido como Parque Buracão, com o título "Percepção dos Usuários do Parque Ecológico "João Domingos Coelho" quanto a Meio Ambiente e Aves" da aluna de graduação da Universidade Júlio de Mesquita Filho, UNESP - Assis, Thaís Soares Cavalieri, forneceu a base para esse projeto, auxiliando na execução de melhorias às necessidades dos frequentadores para a sua inserção ambiental. 
A análise da percepção de Meio Ambiente dos visitantes do parque Ecológico "João Domingues Coelho", antes e após da implantação de placas informativas, que destacam a avifauna local foi o instrumento utilizado para o presente trabalho, assim como a observação de aves como ferramenta didáticopedagógica se adéqua as necessidade e expectativas dos visitantes do Parque, anteriormente a implantação de placas de identificação de aves, e posteriormente a aplicação das mesmas, analisando se essa atividade despertou o interesse e maior percepção sobre a temática ambiental.

O presente estudo teve como objetivo, também, realizar a caracterização do perfil dos visitantes, com a finalidade de identificação de gênero, faixa etária e grau de escolarização; a identificação das características de uso do Parque: tempo de permanência e atividades que desempenham no Parque; a e análise da importância da Educação Ambiental em parques, com o propósito de entender a relação do homem com o meio ambiente, por meio da observação de aves.

\section{Caracterização da Área de Estudo}

A área de estudo se restringe ao Parque Ecológico "João Domingos Coelho", popularmente conhecido como Parque Buracão, situado na cidade de Assis no estado de São Paulo (Figura 1), mas coordenadas: -22 39' 26.31" S, $50^{\circ} 25^{\prime} 38.21 " \mathrm{~W}$.

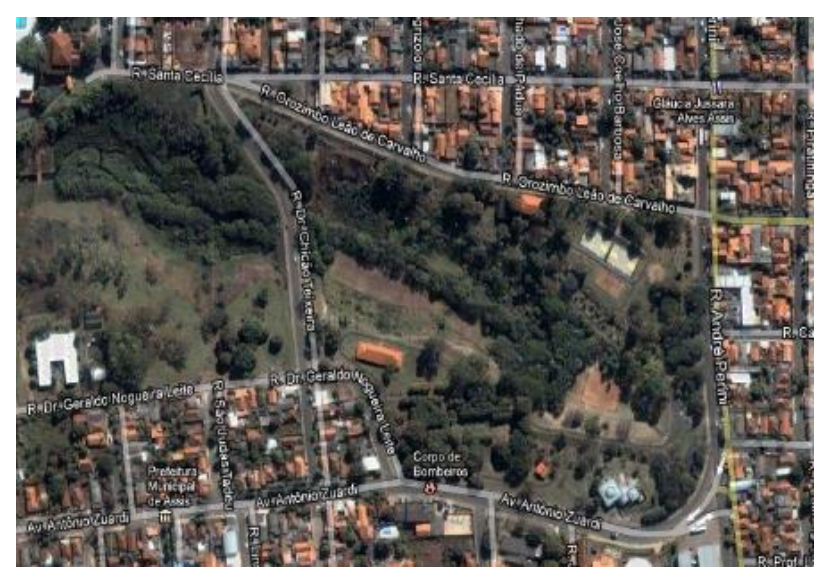

Figura 1: Localização espacial da área do Parque Ecológico “João Domingos Coelho”.Foto de satélite retirada de <http://maps.google.com.br/>, acessado em: 1 de novembro de 2011.

Inaugurado em $1^{\circ}$ de julho de 1999, o Parque abrange uma área total de 91.585 metros quadrados e possui: 50 lixeiras, 80 bancos, anel de caminhada externo e pista de caminhada interna, trilham Ecológica, "play-ground", arena verde, escadarias de acesso à arena, cancha de bocha e malha, mesas para jogos, quadra de areia, duas quadras poliesportivas, quiosques, Sanitários: Feminino e Masculino, eletrificação e iluminação especial, Escola Aberta do Meio 
Ambiente "Álvaro Batista Gomes", Orquidário Municipal "Agostinho Gonçalves Motta", Viveiro de Mudas (SILOTO, 1996).

O parque é um espaço utilizado amplamente para lazer e recreação pela população assisense, desde a sua reforma e inauguração em 1999. Entretanto, encontra-se subutilizado frente às suas possibilidades de uso e suporte pedagógicos. (PRADO, 2003).

\section{Materiais e Métodos}

A fim de auxiliar na execução de ações que consideram as reais expectativas e necessidades do desenvolvimento de um processo educacional que considere toda a complexidade da problemática ambiental, Cavalieri (2011) analisou o perfil e a percepção dos visitantes do Parque Ecológico "João Domingos Coelho", Assis/SP, aplicando um questionário estruturado aos frequentadores em horário de funcionamento das oito horas às 21 horas, em dois turnos (manhã/tarde), nos dias 3, 4, 8, 20, 21, 23 de outubro do ano de 2011. A amostra foi composta de 125 sujeitos de ambos os sexos, com idade acima de 18 anos.

Considerando os resultados, acreditando na viabilização e tendo como base o projeto proposto, esse estudo é uma continuidade prática de Educação Ambiental, a implantação de placas informativas, contendo informações básicas, como hábitos alimentares, nome popular e cientifico, distribuição das espécies e algumas curiosidades das principais aves que habitam o parque ecológico.

Desse modo, realizou-se a mesma coleta de dados do estudo anterior, analisando características do perfil dos usuários, do uso do parque, percepção de ambiente e aves, comparando os resultados anteriores com esse presente estudo.

Com o intuito de analisar se as placas informativas sobre a avifauna local representam um auxílio na construção de ideias para uma sociedade educada ambientalmente, e se a observação de aves despertou o interesse sobre a temática ambiental, sensibilizando os frequentadores do parque, para este projeto foram confeccionadas placas em PVC (Figura no apêndice), com dimensões de $60 \times 40 \mathrm{~cm}$, contendo informações sobre aves. As aves foram previamente escolhidas pela observação da sua prevalência no parque. São elas, Hirunda rustica (Andorinha-de-pescoço-vermelho), Crothopaga ani (Anúpreto), Eupetomena macroura (Beija-flor-tesoura), Aratinga leucophthalma (Periquitão maracanã), Colaptes campestris (Pica-pau-do-campo) e Turdus rufiventris (Sabiá Laranjeira).

As placas foram fixadas no parque ecológico, por meio de abraçadeiras de nylon que as sustentam em árvores localizadas em ambientes de grande fluxo de usuários. As seis placas foram distribuídas em locais de fácil acesso e boa visualização, foram fixadas; nas proximidades do "play ground", na ponte de acesso a quadra de areia, perto cancha de bocha e malha próximos aos 
sanitários, na frente da "academia ao ar livre" e ao redor da sede de aulas disponibilizada pela Secretaria de Meio Ambiente de Assis/SP.

Após sete dias, realizou-se a aplicação de um questionário estruturado (em apêndice) aos frequentadores no horário de funcionamento das oito horas às 21 horas, em dois turnos (manhã/tarde), nos dias 15, 19 e 21 de outubro do ano de 2012. A amostra foi composta de 121 sujeitos de ambos os sexos, com idade acima de 18 anos.

Para análise da Percepção do Ambiente, classificaram-se as palavraschave encontradas nos discursos dos entrevistados, a respeito das concepções de meio ambiente, por meio das tipologias segundo Reigota (1991).

Para diagnóstico da aplicabilidade das placas informativas como instrumento pedagógico e de percepção ambiental, foram analisadas as informações coletadas, comparando com os resultados do trabalho anteriormente realizado por Cavalieri (2011). Foi utilizado o aplicativo Bioestat versão 5 (Ayres), e foi feito análise descritiva por tabelas e gráficos.

\section{Resultados e Discussão}

\section{Características da Amostra Realizada}

A Tabela 1 mostra a distribuição das idades, encontrada na amostra, por números de pessoas nos anos de 2011 e 2012 no Parque Ecológico

Tabela 1: Distribuição das idades por número de pessoas nos anos de 2011 e 2012

\begin{tabular}{ccc}
\hline \multirow{2}{*}{ Idades } & \multicolumn{2}{c}{ Frequência } \\
\cline { 2 - 3 } & $\mathbf{2 0 1 1}$ & $\mathbf{2 0 1 2}$ \\
\hline$<=20$ & 6 & 5 \\
até 30 & 25 & 36 \\
até 40 & 35 & 29 \\
até 50 & 28 & 16 \\
até 60 & 19 & 18 \\
até 70 & 9 & 14 \\
$>70$ & 3 & 3 \\
\hline Total & 125 & 121 \\
\hline
\end{tabular}

A faixa etária prioritariamente encontrada na amostra de usuários do Parque Ecológico “João Domingos Coelho", Assis/SP, está entre 21 e 40 anos de idade, representado por $(53,7 \%)$ do total de usuários, resultado diferente ao encontrado no trabalho de Cavalieri (2011), onde $(66,6 \%)$ do total de usuários pertenciam à faixa etária entre 31 e 60 anos. A diferença apresentada na distribuição das idades por números de pessoas nos anos de 2011 e 2012 pode 
ser explicada pelas instalações recentes de aparelhos de ginástica de uso público. A "academia ao ar livre" é muito utilizada por jovens e adultos, consequentemente aumentando a frequência de usuários dessa faixa etária.

Nos resultados encontrados por Gagetti e Troppa (2011), (11\%) da amostra tem idades entre 21 e 30 anos, diferindo dos resultados encontrados no parque "João Domingos Coelho" Assis/SP, onde (29,7\%) dos frequentadores são inseridos nessa mesma faixa de idade.

Diferente dos resultados encontrados na pesquisa de Morita et al.(2009), no qual somente (2\%) dos usuários pertenciam a faixa etária acima de 60 anos, a presente pesquisa demonstra que o Parque Ecológico de Assis também é amplamente utilizado por esta mesma faixa etária, representando $14 \%$ dos usuários.

A Figura 2 apresenta a distribuição dos gêneros da amostra, no ano de 2012, que visita diariamente o Parque Ecológico conhecido como Buracão.

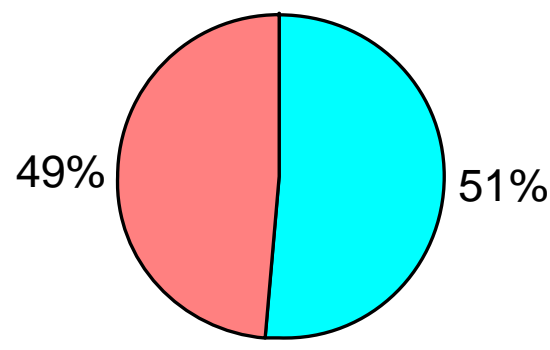

Femino

Masculino

Figura 2: Distribuição dos gêneros.

A amostra dos usuários do Parque Buracão demonstra uma insignificante superioridade no gênero feminino, representando $(51,23 \%)$ (Figura 2.), não se diferenciando dos trabalhos de Cavalieri (2011), onde 56\% dos entrevistados eram mulheres. A distinção de gêneros é mais evidente em trabalhos como o de Gagetti e Troppa (2011), com a pesquisa realizada no Parque da Água Vermelha, na cidade de Sorocaba/SP, que apresenta grande relevância na disparidade de sexos (72\% mulheres), sendo explicado pela resistência dos homens a aceitarem ser entrevistados.

Nos trabalhos de Morita et al. (2009) e também Baasch e João (1997), apresentam pequena superioridade de homens com frequência de $(56 \%)$ e (53.54\%) respectivamente. 
A pequena distinção da frequência entre os gêneros representa que ambos os sexos utilizam os Parques.

Notou-se a prevalência dos gêneros conforme o local onde se localiza no Parque, como em "play-ground", muitas mulheres estão acompanhadas de seus filhos, e em quadras esportivas, cancha de bocha e malha e mesas para jogos 0 gênero masculino predomina.

A Tabela 2 retrata o grau de escolaridade nos anos de 2011 e 2012 na amostra de entrevistados na pesquisa.

Tabela 2: Grau de escolaridade dos entrevistados nos anos de 2011 e 2012

\begin{tabular}{lcccc}
\hline \multirow{2}{*}{ Categorias } & \multicolumn{2}{c}{ número de pessoas } & \multicolumn{2}{c}{$\%$} \\
\cline { 2 - 5 } & $\mathbf{2 0 1 1}$ & $\mathbf{2 0 1 2}$ & $\mathbf{2 0 1 1}$ & $\mathbf{2 0 1 2}$ \\
\hline Analfabeto & 2 & 0 & 1.60 & 0 \\
Fundamental incompleto & 7 & 5 & 5.60 & 4.13 \\
Fundamental completo & 11 & 15 & 8.80 & 12.39 \\
Médio incompleto & 9 & 1 & 7.20 & 0.82 \\
Médio completo & 51 & 63 & 40.80 & 52.06 \\
Superior incompleto & 11 & 10 & 8.80 & 8.26 \\
Superior completo & 34 & 27 & 27.20 & 22.31 \\
\hline Total & 125 & 121 & 100 & 100 \\
\hline
\end{tabular}

Com relação ao Grau de escolaridade, nota-se que no estudo de Cavalieri (2011), uma pequena porção da amostra de usuários do Parque possui grau de escolaridade até ensino médio incompleto, totalizando $(23,2 \%)$ dos usuários. No presente estudo, o percentual de frequentadores do parque com um baixo grau de escolaridade diminuiu em (25.26\%).

Cavalieri (2011), assim como nesse trabalho, a característica encontrada a respeito do grau de escolaridade, em usuários de outros Parques, demonstra resultados similares para mesma faixa de escolaridade, (61\%) Baasc e João (1997) e (60\%) Gagetti e Troppa (2011) op.cit.

O grau de escolaridade dos usuários do parque é muito diferente dos dados divulgados pelo Censo 2010, realizado pelo Instituto de Brasileiro de Geografia e Estatística (IBGE), onde o percentual de pessoas sem instrução ou com o fundamental incompleto é de $(50,2 \%$,) e pessoas com o nível superior completo, chega a $(7,9 \%)$.

\section{Características de Uso do Parque}

A qualidade de vida urbana está diretamente ligada a vários fatores que estão reunidos na infraestrutura, no desenvolvimento econômico-social e aqueles ligados à questão ambiental. No ambiente, as áreas verdes públicas constituem-se elementos indispensáveis para o bem-estar da população, pois 
influência diretamente a saúde física e mental da população (LOBOBA; DE ANGELIS, 2000).

A Figura 3 mostra as principais atividades realizadas no parque nos anos de 2011 e 2012. São descritas, exercitar-se, trazer as crianças para brincas e relaxar.

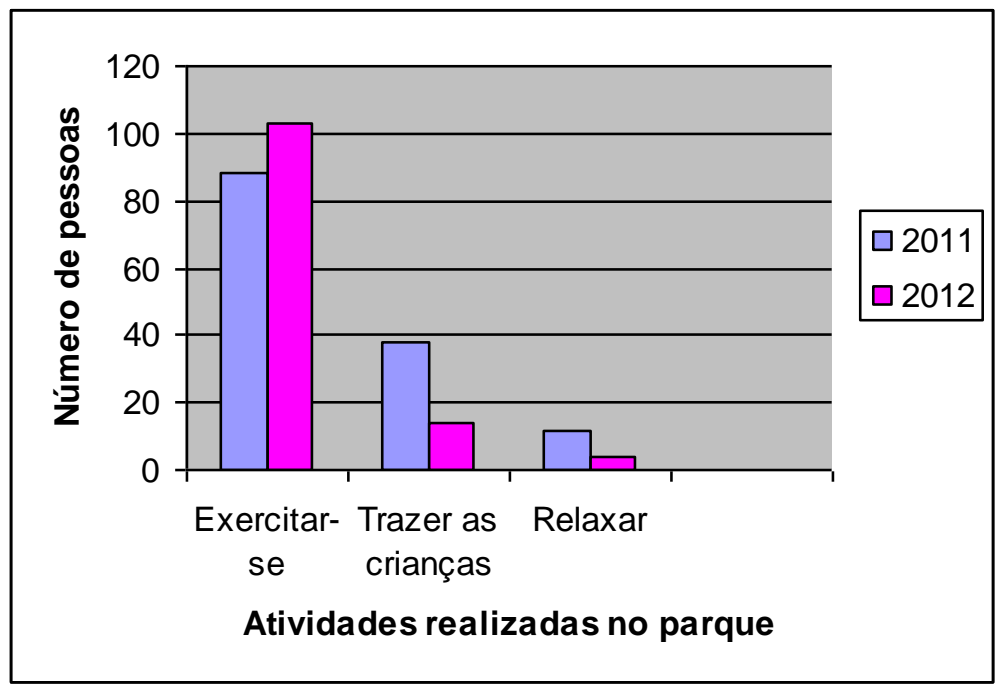

Figura 3: Principais atividades realizadas no parque nos anos de 2011 e 2012.

Muitas são as atividades que podem ser realizadas no Parque, Cavalieri (2011) registrou $(86,3 \%)$ dos entrevistados, utilizando a área prioritariamente para Lazer e recreação (Figura 3), realizando caminhadas, corridas, exercícios, e levando crianças para brincar. No presente trabalho esse índice aumenta, $(96,6 \%)$ dos frequentadores realizam as atividades "exercitar-se", e "trazer as crianças para brincar".

Os resultados se diferem com os encontrados no trabalho de Morita et al. (2009), no qual as atividade mais realizadas também são a prática de esportes $(36,5 \%)$ e brincar com as crianças $(33 \%)$, porém os dados encontrados nesse trabalhos demonstram um superioridade muito maior da atividade "exercitar-se" com relação as demais, apresentando o índice de $(85,1 \%)$. Concluindo assim que o Parque ecológico é amplamente utilizado para caminhadas, corridas, prática de exercício na "academia ao ar livre" e prática de esportes.

Em concordância com as atividades desempenhadas, quase a totalidade da amostra (95,8\%) permanece no Parque por até duas horas (Tabela 3). Os resultados encontrados nos anos de 2011 e 2012 não se diferem quanto ao tempo de permanência no parque. 
Tabela 3: Tempo de permanência no parque nos anos de 2011 e 2012.

\begin{tabular}{ccc}
\hline \multirow{2}{*}{$\begin{array}{c}\text { Tempo } \\
\text { (minutos) }\end{array}$} & \multicolumn{2}{c}{ Número de pessoas } \\
\cline { 2 - 3 } & $\mathbf{2 0 1 1}$ & $\mathbf{2 0 1 2}$ \\
\hline$<=30$ & 4 & 14 \\
até 60 & 71 & 65 \\
até 90 & 23 & 18 \\
até 120 & 23 & 19 \\
até 150 & 1 & 3 \\
$>150$ & 3 & 2 \\
\hline Total & 125 & 121 \\
\hline
\end{tabular}

\section{Percepção do Meio Ambiente}

De acordo com Reigota (1991)

Os termos meio ambiente e Educação Ambiental constantemente utilizados tanto em meios de comunicação como nos discursos políticos, livros didáticos, músicas e outras fontes, demonstram uma grande diversidade conceitual, possibilitando diferentes interpretações, muitas vezes, influenciadas pela vivencia pessoal, profissional e pelas informações veiculadas na mídia, que vão refletir nos objetivos, métodos e/ou conteúdo das práticas pedagógicas propostas no ensino.

A Tabela 4 representa as características segundo a tipologia das concepções de meio ambiente segundo Reigota (1991).

Tabela 4: A tipologia das concepções de meio ambiente segundo Reigota (1991).

\begin{tabular}{cc}
\hline Categorias & Características \\
\hline Naturalista & $\begin{array}{c}\text { Meio Ambiente como sinônimo de natureza intocada } \\
\text { evidencia-se somente os aspectos naturais. } \\
\text { Globalizante }\end{array}$ \\
\hline Antropocêntrica & $\begin{array}{c}\text { Evidencia a utilidade dos recursos naturais para a } \\
\text { sobrevivência do homem. }\end{array}$ \\
\hline É de extrema dificuldade estabelecer uma definição precisa e consensual \\
$\begin{array}{l}\text { devido à complexidade e abrangência das características que englobam o termo } \\
\text { e suas aplicações. }\end{array}$
\end{tabular}


Segundo os PCNs - Parâmetros Curriculares Nacionais (Brasil, 1997) inspirados na Conferencia de Tbilissi (1977) se consideram a respeito do termo Meio Ambiente: aspectos naturais, tecnológicos e sociais (econômico, político, histórico, cultural, técnico, moral e estético). Com isto, na educação o principal não é definir o conceito de Meio Ambiente, mas, explorar suas diversas representações (FIORI, 2006).

A Tabela 5 apresenta as concepções do termo Meio Ambiente dos entrevistados da amostra do Parque Ecológico "João Domingos Coelho", Assis/SP, segundo a tipologia Reigota (1991).

Os resultados encontrados na amostra demonstram que as palavras que estabelecem uma definição a Meio Ambiente fazem referência a componentes associados à dimensão ecológica. Em concordância com a afirmação de Sauvé et al. (2000), que destaca que há uma tendência geral em excluir o ser humano como parte do ecossistema, criando uma noção de ambiente como natureza " pura".

No trabalho exposto houve uma predominância da representação naturalista do meio ambiente $(58,89 \%)$, remetendo o termo a visões do meio como a natureza e seus componentes e recursos, excluindo o ser humano como parte integrante.

Tabela 5: Concepção do termo Meio Ambiente dos entrevistados da amostra do Parque Ecológico “João Domingos Coelho", Assis/SP, segundo a tipologia Reigota (1991).

\begin{tabular}{cccc}
\hline Palavra chave & Frequência & $\%$ & Tipologia \\
\cline { 1 - 3 } Natureza & 56 & 43.4 & Naturalista \\
Lugar onde & & & \\
mora & 14 & 10.85 & Antropocêntrica \\
Árvores/Animais & 13 & 10.07 & Naturalista \\
Lugar em volta & 12 & 9.3 & Antropocêntrica \\
Preservar & 9 & 6,97 & Antropocêntrica \\
Verde & 5 & 3,87 & Naturalista \\
Ar & 3 & 2,32 & Antropocêntrica \\
Interação & 3 & 2,32 & Globalizante \\
Limpeza & 3 & 2,32 & Antropocêntrica \\
Vida & 3 & 2,32 & Antropocêntrica \\
Não sabe & 2 & 1,55 & \\
Paisagem & 2 & 1,55 & Naturalista \\
Saúde & 2 & 1,55 & Antropocêntrica \\
Lazer & 1 & 0,77 & Antropocêntrica \\
Sensações & 1 & 0,77 & Antropocêntrica \\
\hline Total & 129 & 100 & \\
\hline & & &
\end{tabular}


Esta concepção está atrelada ao modelo tradicional de educação, que relaciona diretamente o conceito de meio ambiente com a definição de ecossistema, e negligencia "as explicações das relações humanas com os ambientes biofísicos" (SATO, 1995)

A concepção antropocêntrica (36,77\%) citada pelos usuários do Parque não relaciona o social e o ambiental, mas reconhece as ações transformadoras da sociedade sobre os ecossistemas naturais, estabelecendo assim a interdependência entre os elementos bióticos e abióticos.

Em discordância com o trabalho de Cavalieri (2011), que obteve resultados de predominância na representação antropocêntrica do meio ambiente, $(46,57 \%)$ dos frequentadores subjuga o termo como um cenário para realizações de práticas humanas e como fonte de energia e recursos naturais e $(44,28 \%)$ entende que o ser humano é um observador externo, e não faz interrelações entre a natureza e a sociedade.

Embora o termo muito evidenciado, $(1,55 \%)$ dos entrevistados afirma não saber descrever ou definir o significado do termo.

Demonstrando assim a necessidade de abordar mais sobre Meio Ambiente de forma a esclarecer a relação do conceito com as atividades humanas, desenvolvendo nos indivíduos a aptidão de compreender o ambiente e os elementos bióticos e abióticos, e as relações que podem se estabelecer com o Meio Ambiente, inserido assim, a sociedade, natureza e os animais em um mesmo ecossistema.

Com menor expressividade (2,32\%) encontrou-se no discurso uma visão social integradora, que reconhece uma relação recíproca entre a natureza e sociedade (tipologia globalizante). Resultados semelhantes foram encontrados por Cavalieri (2011), onde (3,05\%) dos frequentadores do Parque remetem o meio ambiente a concepção globalizante.

As análises a respeito das percepções do termo Meio Ambiente apontam para a necessidade do desenvolvimento de um processo educacional que considere a complexidade de significado e as relações com a sociedade, assim como com os animais. Não no âmbito de corrigir as concepções de ambiente, nem para a formulação de um consenso, mas, de ampliar a percepção e superar o senso comum (CHAUí, 2002).

No entanto, mudar a concepção das pessoas sobre um determinado comportamento não é uma tarefa fácil. A escola é um instrumento de transformação social que pode contribuir para esta mudança de valores e atitudes ambientais. Desse modo, os estudos de percepção ambiental apresentam-se como uma ferramenta eficaz para melhor compreender as inter- 
relações entre o homem e o meio, suas expectativas, seus valores, satisfações e insatisfações, necessidades e comportamento (FIORI, 2007).

\section{Percepção das Aves}

O Brasil apresenta a segunda maior biodiversidade de aves no mundo, sendo possuídos de 1822 espécies, das quais 232 exclusivas (endêmicas) dos limites territoriais do País (LOBO, 2008).

As aves são os seres vivos mais bem conhecidos e, portanto mais populares por parte da população brasileira, sendo simpáticas e facilmente observáveis por apresentarem grande diversidade de cores e cantos (STRAUBE; VIEIRA-DA-ROCHA, 2006).

A afirmação acima se confirma no seguinte trabalho na análise da pergunta do questionário estruturado (em apêndice), quanto à observação de aves no Parque Ecológico.

A Figura 4 demonstra a distribuição da observação de aves no parque.

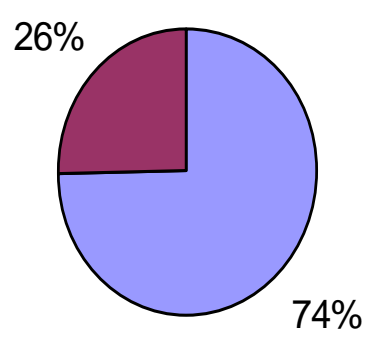

口Observa

Não Obs.

Figura 4: Observação de aves no Parque.

Notou-se uma grande superioridade no número de pessoas que observam a avifauna local no Parque, representando ( $74,38 \%$ dos entrevistados). Tal fato se deve ao carisma que este grupo animal desperta nos indivíduos, por serem facilmente observáveis e apresentarem grande diversidade de cores e cantos (COSTA, 2007). No entanto um número relevante de entrevistado $(25,62 \%)$ declarou não reparar e até desconhecer a presença destes animais no Parque. Resultados semelhantes foram encontrados em Cavalieri (2011).

A Tabela 6 apresenta o conhecimento da avifauna local apresentado em diversas categorias nos anos de 2011 e 2012, no Parque "João Domingos Coelho". 
Tabela 6: Conhecimento da diversidade da avifauna local.

\begin{tabular}{|c|c|c|c|c|}
\hline \multirow[t]{2}{*}{ Categorias } & \multicolumn{2}{|c|}{ Número de pessoas } & \multicolumn{2}{|c|}{$\%$} \\
\hline & 2011 & 2012 & 2011 & 2012 \\
\hline Sabe nomes populares & 43 & 46 & 48.31 & 51.11 \\
\hline Consegue descrever características & 26 & 21 & 29.21 & 23.33 \\
\hline Apenas ouve & 20 & 23 & 22.47 & 25.55 \\
\hline Total & 89 & 90 & 100 & 100 \\
\hline
\end{tabular}

Em comparação com o trabalho de Cavalieri (2011), foram encontrados resultados muito semelhantes. No ano de $2011(48,31 \%)$ dos entrevistados que afirmaram observar aves em visitas ao Parque, souberam expor pelo menos três nomes populares de aves. No trabalho exposto o resultado apresentado é de $(51,11 \%)$.

As respostas "consegue descrever características", e "apenas ouve", também evidenciam a percepção destes usuários quanto a presença das aves, contudo estes entrevistados não possuem nem mesmo o conhecimento popular sobre a ornitologia.

Ingolg (1995) propõe que o contato direto entre o homem e os animais, proporciona a relação "encarnada com a natureza", que é desencadeada pela ativação dos canais sensitivos e afetivos, que pode ocorrer por meio da observação da beleza, dos detalhes de comportamento e morfologia, ou pela vocalização das aves.

A utilização da observação de aves como instrumento didático é fortalecido pela importância ecológica deste grupo zoológico que, além de compor um grupo amplo, atuam significativamente no controle populacional e em inúmeras relações ecológicas de interesse mútuo com vertebrados, invertebrados e plantas (ESPÍNOLA, 2007).

A Tabela 7 apresenta a percepção da importância das aves nas cidades nos anos de 2011 e 2012, onde em ambos os anos a principal categoria citada pelos entrevistados a respeito da serventia das aves no ambiente urbano foi a importância ecológica.

Na presente análise nota-se que no ano de 2012, a porcentagem dessa categoria aumentou significantemente em relação ao ano anterior, $(49,25 \%$ e $31,61 \%$ respectivamente). Comparando este dado com a porcentagem de escolaridade acima de ensino médio, que apresentou um também aumento 
significante, passando de (76,8\%) em 2011, para (82,63\%) no presente estudo, podendo supor que a categoria "importância ecológica" seria citada em porcentagem maior (visto que, está é uma categoria que deveria ser aprendida no ensino escolar), porém, observa-se uma discrepância entre as porcentagens. Demonstrando assim, uma grande defasagem de conhecimento ornitológicos e ecológicos relacionados a serventia das aves na natureza, assim como em ambiente urbanos.

Tabela 7: Percepção da importância das aves nas cidades nos anos de 2011 e 2012.

\begin{tabular}{ccccc}
\hline Categorias & \multicolumn{3}{c}{ Número de pessoas } & \multicolumn{3}{c}{$\%$} \\
\cline { 2 - 5 } & $\mathbf{2 0 1 1}$ & $\mathbf{2 0 1 2}$ & $\mathbf{2 0 1 1}$ & $\mathbf{2 0 1 2}$ \\
\hline Importância ecológica & 49 & 66 & 31.61 & 49.25 \\
Sensações agradáveis & 38 & 29 & 24.52 & 21.64 \\
Embelezamento do ambiente & 33 & 27 & 21.29 & 20.14 \\
Doenças & 23 & 7 & 18.84 & 5.22 \\
Sujeira & 7 & 1 & 4.52 & 0.74 \\
Não sabe & 5 & 4 & 3.23 & 2.98 \\
\hline Total & 155 & 134 & 100 & 100 \\
\hline
\end{tabular}

Segundo Espínola (2007), é de extrema importância tornar comum e frequente a prática de observação de aves, despertando a curiosidade de crianças e jovens para o tema é garantir a preservação dessa diversidade, assumindo significado e grande relevância no cotidiano dos alunos, possibilitando a união da classe aves com o ensino em ciências nas escolas.

Como alerta Rodrigues et al. (2009) a acelerada alteração ambiental representa um fator importante na proliferação de animais transmissores de zoonoses (entre eles, algumas espécies de aves), que se estabelecem em centros urbanos e representam risco a saúde da população. Em face ao exposto, $(5,96 \%)$ dos entrevistados relacionam aves a doenças e a sujeira.

É necessário que se utilize da Educação Ambiental e o conhecimento ornitológico adequado a fim de auxiliar na transmissão de informações necessárias para o convívio saudável entre os seres humanos e os animais.

A percepção das aves está ligada ao campo racional, quando citada em "importância ecológica" e "doenças e sujeira", porém a percepção subjetiva "embelezamento do ambiente" e "sensações agradáveis" tem grande expressividade nos resultados apresentados nos anos de 2011 e 2012, (somando $45,81 \%$ e $41,48 \%$ respectivamente).

Para Costa (2007) a beleza e as sensações agradáveis podem auxiliar na educação, visto que são mais rapidamente reconhecidas informações que representam um prazer do que aquelas que despertem aborrecimento. 
As aves e sua representação no Meio Ambiente, assim como no desempenhar da importância ecológica e na percepção subjetiva apresentam extensas representações no pensamento humano, atribuindo diversos sentidos a prática de observação de aves.

Dos 121 entrevistados no Parque Ecológico João Domingos Coelho, 114, $(94,21 \%)$ demonstraram ter uma imagem psicológica positiva ligada as aves, e apenas um entrevistado declarou perceber aves de forma negativa, alegando 0 muito barulho produzido e as zoonoses ligadas às aves (Tabela 8.). A imagem positiva dos entrevistados constata a sugestão de Argel-de-Oliveira (1997), que as aves não originam aversão as pessoas que em geral outros vertebrados provocam (como morcegos, ratos, anfíbios e répteis), e este fato auxilia na redução do sentimento de rejeição e da noção de que a presença de animais silvestres é perigosa, prejudicial e indesejável.

Analisando os resultados sobre a percepção das aves notou- se que a observação das mesmas, demonstra uma pequena probabilidade de rejeição como agente de sensibilização humana. Segundo Costa (2007) a observação de aves surge como prática pedagógica, oferecendo a possibilidade de ser empregada sob diferentes enfoques e abordagens, resumindo diversas áreas do saber de forma integrada.

\section{Percepção das Placas}

Tuan (1983) argumenta as relações homem e ambiente que definem o ver, pensar e sentir. E essas ações são processos relacionados intimamente, permitindo o indivíduo a "vivenciar o meio". A visão cria estímulos que ativam a percepção do espaço e da realidade, unindo todos os sentidos complementares, o tato, audição e paladar. Desenvolvendo e potencializando interpretações e despertando emoções.

A Figura 5 apresenta a observação das placas da avifauna local fixadas no Parque Ecológico “ João Domingos Coelho”.

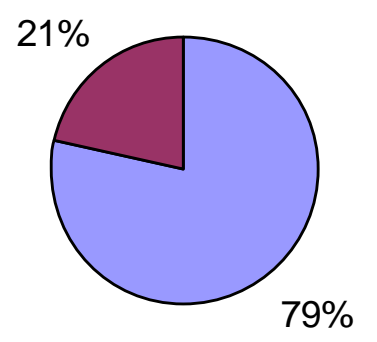

Observa

Não Obs.

Figura 5: Observação das placas da avifauna local fixadas no Parque. 
Face ao exposto, $(79,33 \%)$ dos entrevistados afirmaram a observação das placas sobre a avifauna local fixadas no Parque, em período próximo a aplicação dos questionários. Esse resultado indica um bom aproveitamento frente à proposta educativa, se considerarmos as atividades experimentais, sensitivas e a imaginação, representantes de uma grandiosa relevância em proporcionar a educação emancipatória, pois é amparada por um caráter subjetivo, relativo e pessoal, que segundo Bondía (2002) desenvolve mentes heterogêneas.

Dos 96 entrevistados que alegam a observação das placas da avifauna local, $(41,66 \%)$ afirmam já terem observados no Parque ecológico, pelo menos uma das aves retratadas nas placas. A observação e percepção de placas é um método didático agradável que permite uma assimilação facilitada. Esse procedimento endossa a importância de interação da dicotomia entre 0 pensamento e o conhecimento (SIQUEIRA; PERREIRA, 1995).

Em contrapartida, pode-se propor que o resultado baixo encontrado é definido pela superioridade de usuários do Parque que visitam o local apenas para realização de atividades físicas, não desfrutando da observação de aves. Foi definido por Freire (1985) que o conhecimento exige a presença curiosa do sujeito como integrante do mundo para transformar a realidade. Sendo assim, a aplicabilidade da Educação Ambiental é dependente não apenas de atividades e práticas, mas também do interesse e aproveitamento da sociedade.

Os resultados apresentados na Tabela 8 referem se a serventia atribuída às placas pelos entrevistados.

Tabela 8- Percepção da importância das placas colocadas no parque.

\begin{tabular}{ccc}
\hline Categorias & $\begin{array}{c}\text { Número de } \\
\text { pessoas }\end{array}$ & $\%$ \\
\hline Informação & 107 & 87.77 \\
Importância ecológica & 8 & 6.55 \\
Não sabe & 5 & 4.09 \\
Sensações agradáveis & 2 & 1.63 \\
\hline Total & 122 & 100 \\
\hline
\end{tabular}

Dos 121 usuários que participaram do questionário 107, (87,77\%) afirmaram que a fixação das placas é importante por trazerem informações sobre a avifauna local. Constatando Chassot (2003), afirma que uma linha emergente de estudos e aprendizagem em Ciências, é aquela que comporta o conhecimento cotidiano, permitindo uma melhor compreensão dos fenômenos da natureza.

Dos entrevistados, (97,52\%) alegam que as placas são importantes mecanismos de ascensão ao aprendizado cotidiano. 
A observação de aves no parque é complementada pelas informações descritas nas placas. Desse modo fica evidente que, as placas da avifauna local, fixadas no Parque Ecológico são um instrumento viável para a Educação Ambiental.

No entanto, segundo Quadros (2007), a Educação Ambiental não é compartimentalizada, pois necessita de todas às áreas do conhecimento, e também exige um trabalho conjunto entre a comunidade, o currículo escolar e os poderes políticos, para então a construção de conhecimentos e ações participativas do meio em que vivem, afim de não apenas promoveram a Educação Ambiental, e sim desenvolverem relações solidárias e de respeito e comprometimento com o meio ambiente.

Enfim, quando as portas da percepção se abrir para o mundo, os conflitos naturais exigiram a reconciliação e compreensão do meio e dos seres humanos.

\section{Considerações Finais}

O presente estudo traça o perfil dos usuários do Parque Ecológico "João Domingos Coelho" Assis/SP, analisando a percepção a respeito de meio ambiente e da avifauna local, anteriormente a implantação de placas informativas e, posteriormente à fixação das mesmas. Os resultados encontrados na amostra, a respeito da percepção de Meio Ambiente, apontam para a necessidade do desenvolvimento de um processo educacional, considerando a problemática ambiental e salientando as defasagens de aprendizado escolar, assim como o despertar da curiosidade da sociedade a não apenas criar e entender uma visão do meio como integradora, e sim reconhecer as relações recíprocas entre a natureza e todos os seres vivos.

O trabalho também demonstrou segundo os dados coletados, que a observação de aves, assim como a utilização de placas informativas sobre a avifauna local é um método pedagógico adequado, assim como um instrumento didático que satisfaz aos anseios educacionais, assegurado pela análise psicológica positiva dos frequentadores do Parque em relação à observação de aves e placas.

Considerando os resultados observados na pesquisa, sugere-se além da proposta educativa por meio da utilização das placas informativas, que possuem o intuito de não apenas transferir conteúdos, mas, também complementar o ambiente para a exploração dos conhecimentos ambientais e ornitológicos, esse trabalho serve como base para auxiliar no planejamento e na execução de ações que se encaixam nas reais expectativas e necessidades dos frequentadores.

Ações ambientais que levem em conta as características de uso, assim como atividades que despertam o interesse sobre a temática ambiental, desenvolvem mecanismos necessários que visam entender as relações entre os seres humanos e a natureza. 
Contudo, é importante ressaltar algumas percepções decorrentes das aplicações dos questionários. Apenas um dia após a fixação das placas, em visita ao parque, notou-se que uma das placas foi depredada, na utilização de verniz para pichação. $O$ acontecimento pode ser explicado por um grande número de pessoas que visitam o Parque, e não realizam nenhuma das atividades propostas, e ficam nos lugares com pouca iluminação, muitas realizando atividades imprecisas, mesmo em horário de funcionamento e grande fluxo de pessoas. Infelizmente, a depredação pode ser fruto de pouco ou nenhum conhecimento cultural, ambiental (seja ele derivado do currículo escolar, ou como sujeito integrante do mundo) e da falta de interesse para transformar a realidade do meio. Desse modo, para alguns usuários do Parque, a fixação das placas não acarretou na sua real importância, já que a aplicabilidade da Educação Ambiental é dependente não apenas de atividades práticas, mas também da curiosidade e aproveitamento da sociedade.

Essa situação é também recorrente pela falta de preocupação e ações dos órgãos gestores que não possibilitam mais segurança aos frequentadores.

Outro relato que prevaleceu nos questionários foi à indignação dos entrevistados quanto à infraestrutura do Parque, que visivelmente não corresponde às necessidades dos usuários, foi em grande quantidade citado, a ausência do funcionamento dos banheiros, a pouca iluminação noturna, visto que muitos usuários utilizam o local durante a noite, também foi descrito a falta de preocupação com as paisagens naturais e a limpeza do Parque, assim como a poluição visual resultado das pichações numerosas.

A melhoria dos recursos de infraestrutura e do processo de Educação Ambiental contínuo, poderia estimular os momentos de lazer e a sensibilização ao desenvolvimento da percepção.

A harmonia dos elementos da natureza interagindo beneficamente faz parte da luta pela sustentabilidade e o desenvolvimento da consciência ecológica, respeito e amor ao planeta

\section{AGRADECIMENTOS}

À Universidade Júlio de Mesquita Filho, por me ajudar a me tornar bióloga e mestre em Ciências Ambientais, à companhia de tratamento de água SABESP por subsidiar a pesquisa e a amiga Thaís pela inspiração. 


\section{REFERÊNCIAS}

ARGEL-DE-OLIVEIRA M. M. 1997. El uso de aves em Educación Ambiental. Anais do Encuentro Boliviano para la Conservación de las Aves. Santa Cruz de la Sierra. Armonía. 1997. 27-30 p.

BAASCH, S.S.N.; JOÃO, C.G. Valoração do Meio Ambiente. Um estudo de caso: O Parque do Rio Vermelho- Florianópolis-S". Anais do $19^{\circ}$ Congresso Brasileiro de Engenharia Sanitária e Ambiental ABES- Associação Brasileira de Engenharia Sanitária e Ambiental, VI- 052: setembro/1997. 2502- 2513 p.

BRASIL. Ministério da Educação. Parâmetros Curriculares Nacionais: meio ambiente, saúde. Secretaria de Educação Fundamental. Brasília:MEC, 1997.

BONDÍA, J.L. Notas sobre a experiência e o saber de experiência. Revista Brasileira de Educação, n.19, 2002.

CAPRA, F. A teia da vida São Paulo: Cultrix, 1994.

CAVALIERI, T.S. Percepção dos usuários do Parque Ecológico "João Domingos Coelho" Assis/SP, quanto a meio ambiente e aves. Monografia em Bacharelado em C. Biológicas na Universidade Júlio de Mesquita Filho - UNESP - Assis - SP, 2011

CHASSOT, A.I. Alfabetização científica: uma possibilidade para a inclusão social. Revista Brasileira de Educação, no 22, São Paulo - SP, 2003.

CORREA, R.L.; ROSENDAHL, Z. Paisagem, tempo e cultura. Rio de Janeiro: EdUerj, 1998.

CHAUÍ, M. Convite à filosofia. São Paulo, Ática, 2002.

COSTA, R.G.A. Observação de Aves como Ferramenta didática para Educação Ambiental. Revista Didática Sistêmica, ISSN 1809- 3108 (Volume 6): julho a dezembro/2007. 33-44 p.

DIAS, G.F. Atividades interdisciplinares de Educação Ambiental. São Paulo, Gaia, 2006.

Espínola, C.R.R. Aves na escola, análise de livros didáticos do ensino fundamental. Florianópolis, 2007.

FIORI, A. A percepção Ambiental como instrumento de apoio de programas de Educação Ambiental da Estação Ecológica de Jataí (Luiz Antônio, SP). Tese (doutorado) - Programa de Pós-Graduação em Ecologia e Recursos Naturais, Universidade Federal de São Carlos. São Carlos. 2006.

FREIRE, F.F. Os estudos do imaginário e as organizações educacionais. Coletânea de Artigos Científicos. Rio de Janeiro: Centro de Estudos de Pessoal, 2006.

GAGETTI, B.L.; TROPPA, R.H. Caracterização do Perfil e avaliação da percepção ambiental de moradores do entorno e usuários do Parque Municipal Água Vermelha“João Câncio Pereira", Sorocaba, S". Anais do X Congresso de Ecologia do Brasil, São Lorenço- MG, Setembro/ 2011.

IBGE. Manual Técnico da Vegetação Brasileira. Rio de Janeiro, 1992.

INGOLD, T. "Humanidade e animalidade". In: Revista Brasileira de Ciências Sociais, $n^{\circ}$ 28, 1995. 39-52 p. 
LOBO,F. E o Brasil descobre a sua fauna alada, 2008.

LOBODA, C.R.; ANGELIS, B.L.D. Áreas verdes públicas urbanas: Conceitos, usos e funções. Revista do Centro de Ciências Agrárias e Ambientais, Ambiência Guarapuava, PR v.1 n.1. jan./jun. 2005. 125-139 p.

MELAZO, G.C. Percepção Ambiental e Educação Ambiental: Uma Reflexão sobre as relações interpessoais e ambientais no espaço urbano. Olhares \& Trilhas. Uberlândia, N.6 (VI). 2005. 45-51 p.

MORITA, I. M. et al. Percepção Ambiental da área verde Parque da Mantiqueira. Anais do XXI Congresso de Iniciação Científica da UNESP. São José do Rio PretoSP. Novembro/2009. 06626- 06629 p.

QUADROS, A. "Educação Ambiental: Iniciativas populares e cidadania" Santa Maria - RS ; Março/2007.

OLIVEIRA, K. A.; CORONA, H. M. P. Percepção Ambiental como ferramenta de propostas educativas e de políticas ambientais. Revista Científica ANAP Brasil ISSN 1984-3240 Ano 1 No1. julho/2008. 53- 72 p.

PRADO, A.L.A.; MORELI, M.M.N. Assis: passado, presente e futur". Assis; Conosco. 2003.

REIGOTA, M. O que é Educação Ambiental. São Paulo: Brasiliense. 1991.

RODRIGUES, J.G.; ESTON, M.R.; MARCONDES, M.A.; MENDES A.F. A Percepção dos visitantes do Parque Estadual Alberto Lofgren- São Paulo em relação à presença de pombos domésticos Columba livia domestica como vetores de Zoonoses. Anais do III Seminário de Iniciação Científica do Instituto Florestal.2009.

SATO, M. Educação Ambiental. 3. ed. São Carlos: PPG-ERN/UFSCar. 1995.

SAUVÉ L. et al. La educación ambiental: una relación constructiva entre la escuela y la comunidad. Montreal: EDAMAZ e UQÀM. 2000.

SILOTO, R.S. Urdiduras e Tessituras. Na história das cidades, a estruturação territorial de Assis. Tese (Doutorado em História) Faculdade de Ciências e Letras, Universidade Estadual Paulista. Assis. 1996. 351 p.

SIQUEIRA; H.S.G.; PEREIRA, M. A. A Interdisciplinaridade como superação da fragmentação. Caderno de Pesquisa, no 68 - Setembro, 1995.

STRAUBE, F.C.;VIEIRA-DA-ROCHA, M.C. O conhecimento da avifauna pela população de Curitiba (Paraná, Brasil), como subsídios para propostas locais de Educação Ambienta. Atualidades Ornitológicas On-line. ISSB 1981-8874,(N 133). maio/ 2006. 29-40 p.

TUAN, Yi-Fu. Topofilia: um estudo da percepção, atitudes e valores do meio ambiente. São Paulo: Difel, 1980.

VIEIRA-DA-ROCHA, M.C.; MOLIN, T. A aceitação da observação de aves como ferramenta didática no ensino formal. Atualidades Ornitológicas On-line. ISSB 1981-8874. (N 146). Novembro a dezembro/2008. 33-37 p. 


\section{Apêndice}

Questionário estruturado utilizado na presente pesquisa.

\section{unesp}

\section{UNIVERSIDADE ESTADUAL PAULISTA "JÚLIO DE MESQUITA FILHO"}

Exemplo de Imagem de Placa

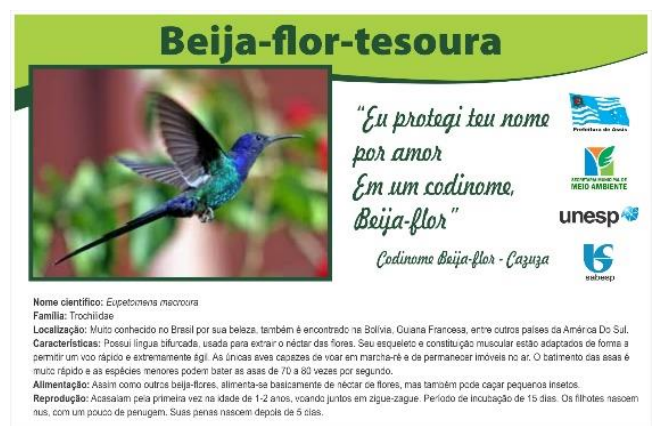

Seg ( ) Ter ( ) Quar ( ) Qui ( ) Sex ( ) Sáb ( ) Dom ( ) ----- $\quad$ Manhã ( ) Tarde ( )

\section{QUESTIONÁRIO:}

\section{PERFIL}

1) Sexo: $F(~) M(~)$

2) Idade

3) Grau de escolaridade:

Analfabeto ( ) Fundamental incompleto ( ) Fundamental completo ( )

Médio incompleto ( ) Médio completo ( )

Superior incompleto ( ) Superior completo ( )

CARACTERÍSTICAS DE USO:

4) Quanto tempo permanece no Parque Buracão:(Minutos)

5) Quais atividades realiza no Parque Buracão:

Andar/exercitar-se ( ) Relaxar/refletir( ) Ler( ) Apreciar a

natureza/paisagem( )

Namorar( ) Trazer crianças para brincar ( )

PERCEPÇÃO DO AMBIENTE:

6) Descreva o que é Meio Ambiente: 
PERCEPÇÃO DE AVES:

7) Quais pássaros já observou neste local:

8) Se observou:

Sabe os nomes populares ( ) Consegue descrever características ( )

Apenas ouve ( )

Não repara nisso ( ) Outros

9)O que sente, ou pensa quando vê aves:(Imagem psicológica

Positiva ( ) Negativa ( ) Neutra ( )

10)Para que servem os pássaros na cidade:

( ) Importância ecológica ( ) Embelezamento do ambiente (visual)

( ) Sensações agradáveis ( ) Doenças ( ) Sujeira ( ) Não Sabe

PERCEPÇÃO (PLACAS):

11) Reparou as placas informativas da avifauna local, recentemente colocadas no parque?

12) Se sim, já viu os pássaros retratados no parque?

Sim ( ) Não ( )

13) Para que servem as placas informativas da avifauna local, recentemente colocadas no parque?

Importância ecológica ( ) Embelezamento do ambiente (visual) ( ) Informação ()

Sensações agradáveis ( ) Poluição visual ( ) Outro ( ) Não Sabe ( )

15) Acredita que as placas são um bom instrumento de Educação Ambiental?

Sim ( ) Não ( ) 